\title{
CLINICAL STUDY OF ACUTE POISONING
}

Panduranga M. S1, Rangaswamy²

\section{HOW TO CITE THIS ARTICLE:}

Panduranga M. S, Rangaswamy. "Clinical Study of Acute Poisoning". Journal of Evolution of Medical and Dental Sciences 2014; Vol. 3, Issue 45, September 18; Page: 11028-11039, DOI: 10.14260/jemds/2014/3439

ABSTRACT: BACKGROUND AND OBJECTIVE: Acute poisoning is an important medical emergency. Studies of this nature will be useful tool in planning, early diagnosis and management of acute poisoning cases. The objective of the study are to study the clinical features, diagnosis and management, morbidity and mortality of various acute poisoning. METHODOLOGY: This study comprises of 350 patients of acute poisoning admitted to Chigateri General Hospital and Bapuji Hospital attached to J. J. M. Medical College, Davangere, between 1st March 2011 to 31 ${ }^{\text {st }}$ October 2011. REUSLTS: Out of 350 cases of acute poisoning studied, there were 268 males and 82 females. Males comprised $76.57 \%$ and females $23.42 \%$ of the total, in this series, Organophosphorous compounds were the commonest (30\%), majority of the patients hailed from rural area $70 \%$. Mortality is $10.57 \%$.

INTRODUCTION: The advance in science has brought out several effects on human life, most of which are beneficial to mankind. It also has caused indirectly ill effects on human life. Acute poisoning by chemicals and drugs is one such example. ${ }^{1}$

Acute poisoning by chemicals and drugs is one of the common emergencies encountered in most of the hospitals in the country. This carries high mortality and morbidity if early recognition and intervention is not done Owing to this development in the field of chemistry and pharmacology a significant number of new compounds has appeared in the industry and medicine. ${ }^{2}$

The spectacular action of these compounds as insecticides an pesticides paved the way for new compounds. Extensive use of these poisonous compounds has resulted in large number of people coming in contact with such substances in their daily life. In recent times the effect of changing life style and values in life and human relationship is also one of the contributing factors for consumption of such drugs and medicines with a suicidal intention. ${ }^{3}$

All these factors lead to the new problems of increased incidences of poisoning either accidental or suicidal.

Among the drugs and chemicals, following are consumed with suicidal intention or accidental are in following order. ${ }^{4}$

1. Organo-phosphorous compounds (O.P. compounds).

2. Therapeutic drugs like anti epileptics, psychotropic drugs etc.

3. Acids and alkalies.

4. Miscellaneous substances.

Among the above compounds, organophosphorous compound poisoning is the most common acute poisoning. These organophosphorous compounds have gained popularity as "poison of choice" for suicidal purposes. These are easily available in the open market without prescription and they are quite cheap. ${ }^{5}$

Rapid industrialization and exposure to hazardous chemical products, introduction of newer range of drugs for treatment, massive use of pesticides in agriculture, increased alcohol consumption, 
unhealthy dietary habits has widened the spectrum of toxic products to which people have been exposed as compared with the early days. ${ }^{6}$

Knowingly or unknowingly millions of people are exposed to danger by hazardous occupational practices and unsafe storage, of toxic chemicals products in their day to day life. Lack of specialized toxicological services in developing countries like India has further contributed to the higher rate morbidity and mortality. ${ }^{7}$

According to WHO (1999) more than three million poisoning cases has been reported out of which 251, 881 deaths occur worldwide annually, of which, 99\% of fatal poisoning occur in developing countries, predominantly among farmers due to various kinds of poisoning, including poisonous toxins from natural products are handled. Therefore, an alarm for early diagnosis, treatment and prevention is crucial in reducing the burden of poisoning related injury in any country. ${ }^{8}$

A comparative data revealed that in developed countries, the mortality rate due to poisoning is only $1 \%$ to $2 \%$, but in developing countries like India it varies between $15 \%$ to $30 \%$ and is the fourth most common cause of mortality especially in rural India. ${ }^{9}$

\section{OBJECTIVES:}

The aims of the study of acute poisoning are as follows:

- To study the clinical features, diagnosis and management of acute poisoning.

- To study the morbidity and mortality of various acute poisoning.

- To study the form of poison and purpose of consumption.

- To study the relative incidence of acute poisoning.

- To study occupation, gender and age distribution of acute poisoning.

METHODOLOGY: This study comprises of 350 patients of acute poisoning admitted to Chigateri General Hospital and Bapuji Hospital attached to J.J.M. Medical College, Davangere, between $1^{\text {st }}$ March 2011 to $31^{\text {st }}$ October 2011. All the patients who satisfied the following inclusion criteria were included

All cases of acute poisoning admitted to the medical ward of Chigateri General Hospital and Bapuji Hospital attached to J.J.M. Medical College, Davangere, between 1 ${ }^{\text {st }}$ March 2011 to 31 ${ }^{\text {st }}$ October 2011. (Total of eight months). Diagnosis of acute poisoning was made from the history of ingestion of poison, circumstantial evidence, characteristic odour of the poison and clinical assessment of the patient.

History was obtained from the patients and the attenders regarding the type of the poison consumed approximate amount of the poison ingested and the intention of poisoning.

History was also taken regarding any associated drug or alcohol ingestion. Interval between the time of ingestion and time of hospitalization was noted down.

Address and occupation of the patient was noted and the patient was classified into 'urban' if he hailed from city corporation limits and 'rural' if he was residing outside city corporation limits.

Clinical assessment was done soon after admission and patient was assessed specifically for level of consciousness, pulse rate, pulse rhythm, respiration, blood pressure, papillary size and papillary reaction to light and for presence of fasciculation. Patient was also examined for the 
evidence of complications like gastritis, aspiration pneumonia etc at the time of admission. Blood barbiturate levels measured in its poisoning.

Patient was managed depending on the nature of compound ingested and the clinical condition at admission. Specific antidotes like atropine, P2AM were administered whenever necessary.

Supportive therapy was given to all patients as described in part I In addition, patients with history of associated alcohol ingestion were administered inj. Thiamine 100mg intravenously and patients with Datura poisoning were given inj. Diazepamn. S mg by slow intravenous or by intra muscular route.

Forced alkaline diuresis was induced in those who had consumed toxic doses of long acting barbiturates, salicylates and lithium.

In uncomplicated cases, the patient was treated with general supportive care and specific antidotes wherever necessary, monitored and was discharged after complete recovery

At the time of discharge the patient was reevaluated and classified into complete recovery or with residual complications.

In the event of death of the patient, the time and cause of death were noted.

Statistical Methods: The data obtained was analysed by descriptive statistics by means of percentage, proportions and depicted via bar charts, pie charts.

Type of study: Observational study.

\section{SELECTION OF SUBJECTS:}

INCLUSION CRITERIA:

- Any patient aged above 16 years.

- Patient bought to the hospital within 24 hours of exposure to poison.

- Patients who do not have any associated serious systemic illness.

\section{EXCLUSION CRITERIA:}

- Cases with chronic poisoning

- Patient with another primary diagnosis such as trauma, even if there is additional acute poisoning.

REUSLTS: Out of 350 cases of acute poisoning studied, there were 268 males and 82 females. Males comprised $76.57 \%$ and females $23.42 \%$ of the total. Majority of the patients were in age group of 20 30 years. Minimum age was 18 years and maximum age 60 years. The average age was 26.5 years. Poisoning was mainly seen in the productive age group. These are shown in table no.1 below.

\begin{tabular}{|c|c|c|c|c|c|}
\hline Series No. & Age group (in years) & Males & Female & Total & Percentage \\
\hline 1 & $18-24$ & 124 & 50 & 174 & 49.71 \\
\hline 2 & $25-34$ & 72 & 21 & 93 & 26.57 \\
\hline 3 & $35-44$ & 43 & 10 & 53 & 15.14 \\
\hline
\end{tabular}


ORIGINAL ARTICLE

\begin{tabular}{|c|c|c|c|c|c|}
\hline 4 & $45-54$ & 24 & 1 & 25 & 7.14 \\
\hline 5 & $>55$ & 5 & 0 & 5 & 1.42 \\
\hline Total & \multicolumn{2}{|c|}{ Table 1: Age and sex wise distribution } & $\mathbf{8 2}$ & $\mathbf{3 5 0}$ & $\mathbf{1 0 0}$ \\
\hline
\end{tabular}

Various compounds were consumed by the patients for the purpose of poisoning. These were analysed in our study group. In this series, Organophosphorous compounds were the commonest (30\%), followed by rat poison (16\%), carbamates (15\%), hypnosedative $(15 \%)$, therapeutic drugs $(9 \%)$, plant poison $(6 \%)$, organochlorine $(3 \%)$, corrosive $(2 \%)$ and petroleum products and miscellaneous $2 \%$ each. This has been reflected in the graphical form in next page.
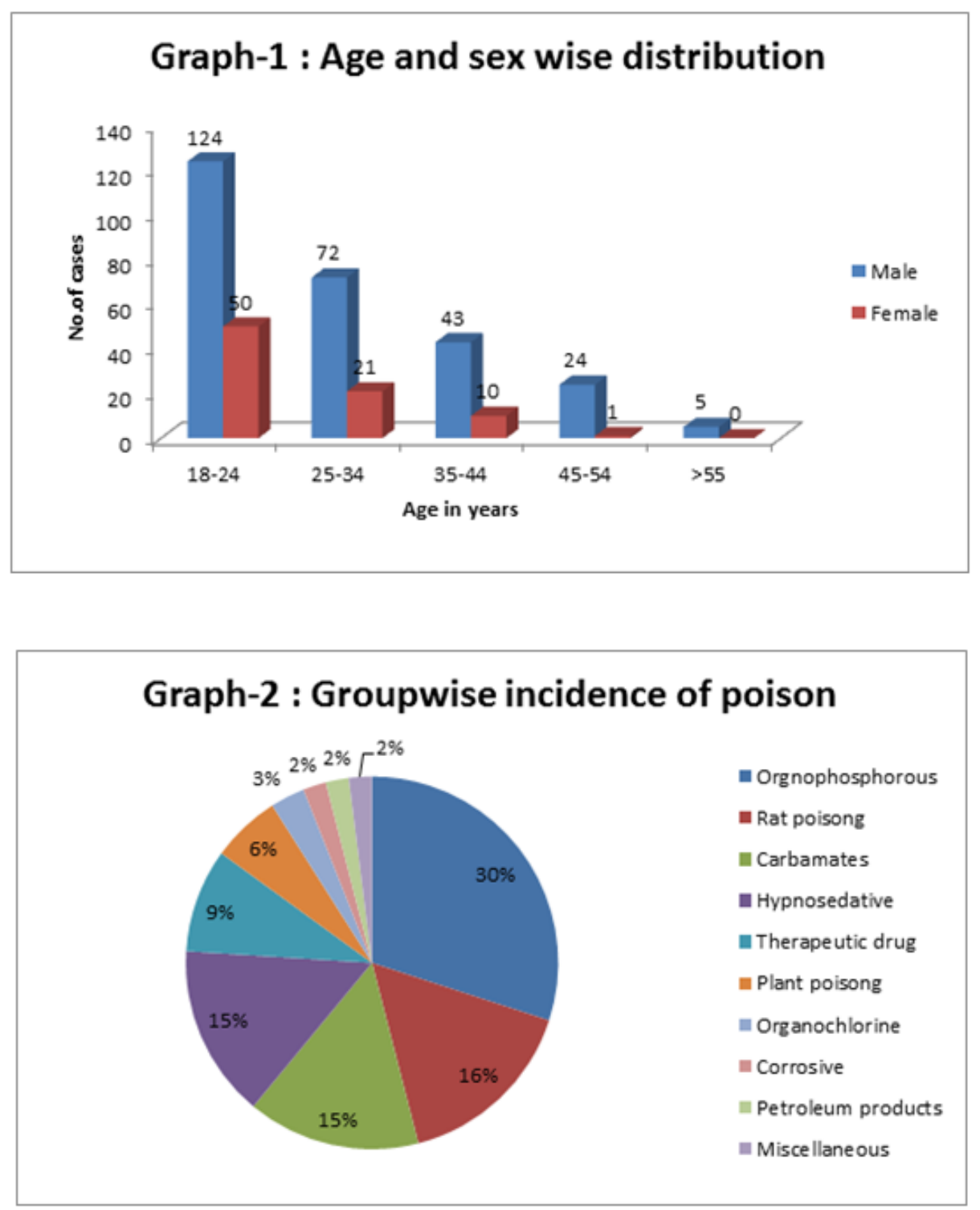

The patients were grouped into urban and rural as outlined earlier. In this study majority of the patients hailed from rural area $70 \%$. This could be attributed to the study center being located in 


\section{ORIGINAL ARTICLE}

the heart of the city, better transport facilities from rural areas, reputation of the institution and may be due to increased stress and strain of rural life. This is reflected graphically below.

\section{Graph-3 : Urban - Rural ratio of cases}

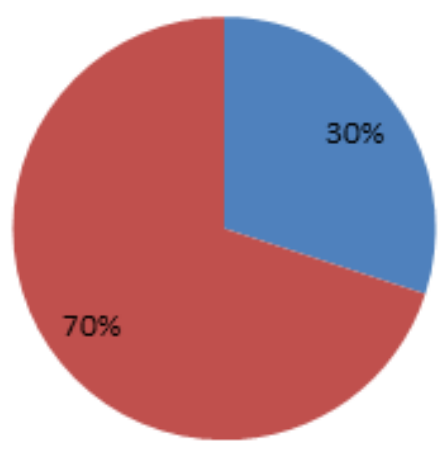

urban

nural

By occupation $45 \%$ were farmers, $25 \%$ were manual laborers, $10 \%$ housewives, $9 \%$ businessmen, $6 \%$ students, another $5 \%$ include unemployed and Govt. employee and others.

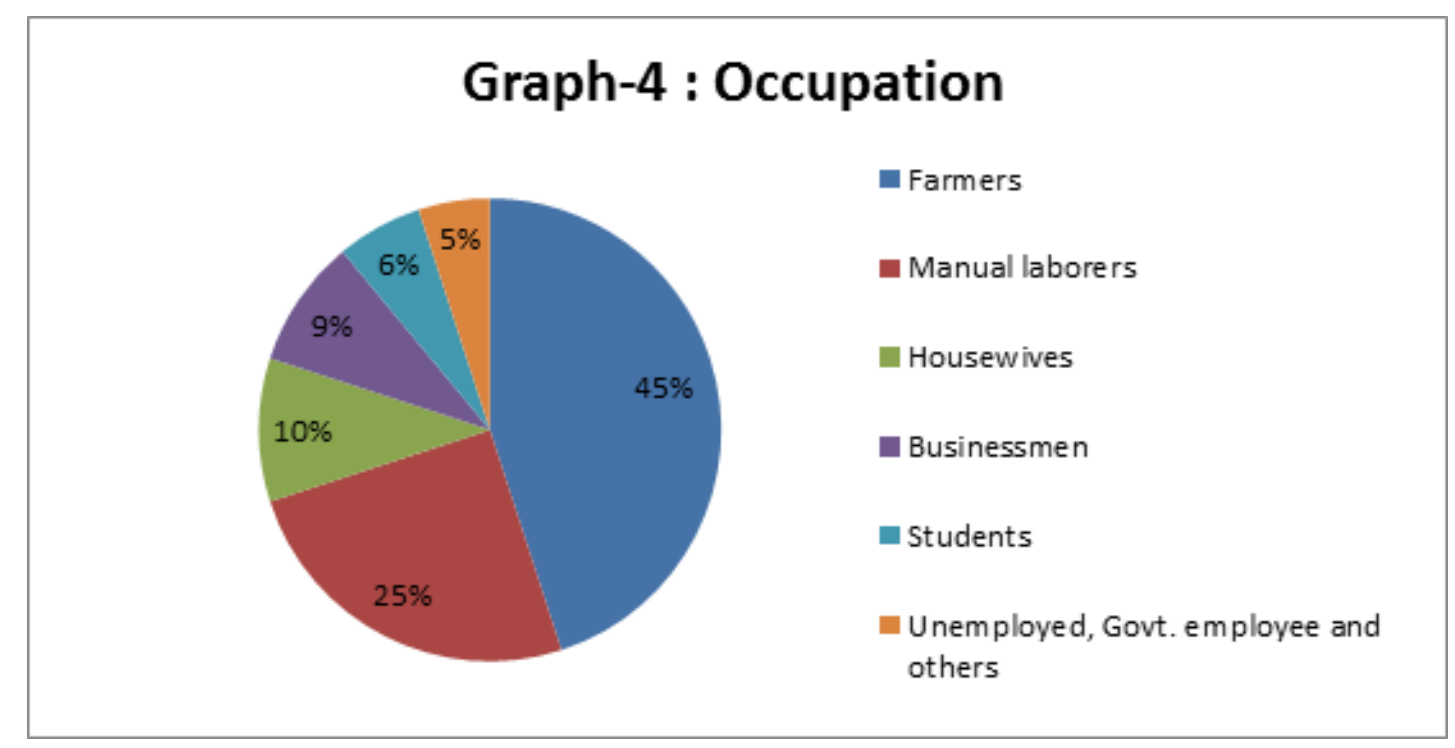




\section{ORIGINAL ARTICLE}

\begin{tabular}{|c|c|c|c|c|}
\hline $\begin{array}{l}\text { Sl. } \\
\text { No. }\end{array}$ & \multicolumn{2}{|c|}{$\begin{array}{l}\text { Clinical } \\
\text { feature }\end{array}$} & $\begin{array}{c}\text { No. of } \\
\text { Patients }\end{array}$ & $\begin{array}{l}\text { Percentage of } \\
\text { total patients }\end{array}$ \\
\hline \multirow{3}{*}{1} & \multirow{3}{*}{ Level of consciousness } & Conscious & 218 & 62.28 \\
\hline & & Altered sensorium & 112 & 32 \\
\hline & & Coma & 20 & 5.71 \\
\hline \multirow{3}{*}{2} & \multirow{3}{*}{ Pulse rate } & $<60$ & 30 & 8.57 \\
\hline & & $60-100$ & 268 & 76.57 \\
\hline & & $>100$ & 52 & 14.85 \\
\hline \multirow{3}{*}{3} & \multirow{3}{*}{ Blood pressure } & Normal & 329 & 94 \\
\hline & & Hypotension & 21 & 6 \\
\hline & & Hypertension & 0 & 0 \\
\hline \multirow{3}{*}{4} & \multirow{3}{*}{ Respiratory rate } & $<14$ & 7 & 2 \\
\hline & & 14-18 & 339 & 96.85 \\
\hline & & $>18$ & 4 & 1.14 \\
\hline \multirow{3}{*}{5} & \multirow{3}{*}{ Pupil size } & Normal & 140 & 40 \\
\hline & & Constricted & 201 & 57.42 \\
\hline & & Dilated & 9 & 2.57 \\
\hline \multirow{2}{*}{6} & \multirow{2}{*}{ Pupil reaction } & Reactive & 160 & 45.71 \\
\hline & & Non-reactive & 190 & 54.28 \\
\hline \multirow{2}{*}{7} & \multirow{2}{*}{ Fasciculation } & Present & 42 & 12 \\
\hline & & Absent & 308 & 88 \\
\hline \multirow{2}{*}{8} & \multirow{2}{*}{ Epigastric tenderness } & Present & 250 & 71.42 \\
\hline & & Absent & 100 & 28.57 \\
\hline \multirow{2}{*}{9} & \multirow{2}{*}{ Signs of aspiration } & Present & 30 & 8.57 \\
\hline & & Absent & 320 & 91.42 \\
\hline
\end{tabular}

\section{Graph-5 : Level of consciousness}

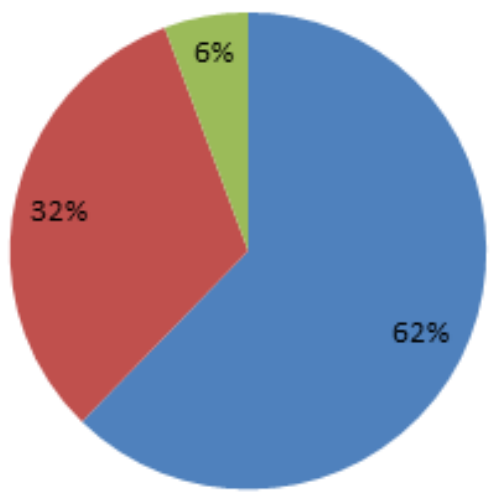

Conscious

Atlered sensorium

coma 
Specific antidotes like Inj. Atropine and Inj. Oxime were given in organophosphorous compound poisoning.

Supportive care was given to all the patients depending on the nature of compound and their clinical condition. Further absorption of the poison was prevented by thorough body wash and gastric lavage or aspiration. Blood barbiturate levels were measured in 12 phenobarbitone poisoning.

Minimum level was $3.5 \mathrm{mg} / 100 \mathrm{ml}$ and maximum of $7.0 \mathrm{mg} / 100 \mathrm{ml}$, and average of $5 \mathrm{mg} / 100 \mathrm{ml}$ and 1 patient with $7.0 \mathrm{mg} / 100 \mathrm{ml}$ went for renal failure, referred to other hospital for dialysis and patient recovered. Enhancement of poison elimination was done in certain cases by means of forced alkaline diuresis. Intravenous fluids, injection $\mathrm{H} 2$ blockers and prophylactic antibiotics were given whenever indicated. These are reflected in the table no.3.

\begin{tabular}{|c|l|c|c|}
\hline $\begin{array}{c}\text { Sl. } \\
\text { No. }\end{array}$ & \multicolumn{1}{|c|}{$\begin{array}{c}\text { Supportive } \\
\text { treatment }\end{array}$} & $\begin{array}{c}\text { Number of } \\
\text { patients }\end{array}$ & Percentage \\
\hline 1 & Thorough body wash & 251 & 71.71 \\
\hline 2 & Gastric lavage & 290 & 82.85 \\
\hline 3 & Gastric aspiration & 80 & 22.85 \\
\hline 4 & Intravenous fluids & 343 & 98.1 \\
\hline 5 & H2 blockers & 320 & 91.42 \\
\hline 6 & Antibiotics & 310 & 88.57 \\
\hline 7 & Inj. Thiamine & 80 & 22.85 \\
\hline 8 & Inj Diazepam & 18 & 5.14 \\
\hline 9 & Inj Dopamine & 10 & 2.85 \\
\hline 10 & Forced Alkaline Diuresis & 12 & 3.42 \\
\hline
\end{tabular}

Table 3: Type and percentage of supportive treatment given to the patients

Whenever the patient's condition warranted further specialized care like ventilatory support, dialysis etc., patient was referred to institutions where such facilities were available. In our study, 20 patients constituting $5.71 \%$ of the total patients required such care. All the referred patients were followed up and all of them recovered. This has been reflected in table no 4 below.

\begin{tabular}{|c|c|c|c|c|c|}
\hline $\begin{array}{c}\text { Poison } \\
\text { consumed }\end{array}$ & $\begin{array}{c}\text { Total No. of } \\
\text { patients }\end{array}$ & $\begin{array}{l}\text { Number } \\
\text { referred }\end{array}$ & $\begin{array}{c}\text { Reason for } \\
\text { referral }\end{array}$ & $\begin{array}{l}\text { Percentage of } \\
\text { total patients }\end{array}$ & Outcome \\
\hline OPC & 105 & 13 & $\begin{array}{l}\text { Ventilatory } \\
\text { support }\end{array}$ & 12.38 & $\begin{array}{l}10 \text { recovered ( } 3 \\
\text { expired) }\end{array}$ \\
\hline Carbamate & 53 & 6 & $\begin{array}{l}\text { Ventilatory } \\
\text { support }\end{array}$ & 11.32 & $\begin{array}{l}5 \text { recovered (1 } \\
\text { expired) }\end{array}$ \\
\hline $\begin{array}{l}\text { Hypno } \\
\text { sedative }\end{array}$ & 52 & 1 & $\begin{array}{l}\text { Haemo- } \\
\text { dialysis }\end{array}$ & 1.92 & Recovered \\
\hline \multicolumn{2}{|c|}{$\begin{array}{c}\text { Total number of acute } \\
\text { poisoning } 350\end{array}$} & \multicolumn{2}{|c|}{$\begin{array}{c}\text { Total number of referred } \\
\text { patients } 20\end{array}$} & \multicolumn{2}{|c|}{$5.71 \%$ (of all patients) } \\
\hline
\end{tabular}

The average hospital stay of the patient in our series was 3.5 days. The analysis of the data with respect to the days in hospital is presented below 


\begin{tabular}{|c|c|}
\hline Hospital stay & Duration in days \\
\hline Minimum stay & 1 \\
\hline Maximum stay & 21 \\
\hline Average stay & 3.5 \\
\hline
\end{tabular}

Table 5: Duration of hospitalization in acute poisoning cases

In spite of general measures, supportive treatment and specific therapy, 37 deaths were observed in the present study period from $1^{\text {st }}$ March 2011 to $31^{\text {st }}$ October 2011. These constituted $10.57 \%$ of total number of acute poisoning as shown in the table number 6 .

\begin{tabular}{|c|c|c|}
\hline Total number of patients & Number of deaths & Percentage \\
\hline 350 & 37 & 10.57 \\
\hline \multicolumn{2}{|c|}{ Table 6: Mortality rate of acute poisoning } \\
\hline
\end{tabular}

Analysis of the deaths based on the type of poison consumed was done and reflected in figure no.

In our series, the mortality rate was $10.57 \%$.Further analysis of the deaths placed on the area of residence showed an interesting result. Of the total 245 patients belonging to rural areas, there were 25 deaths giving a mortality rate of $67.56 \%$. But there were 12 deaths out of 105 patients hailing from rural areas which gives a mortality rate of $32.43 \%$. These are graphically depicted in the figure

The deaths were also analyzed with respect to the time interval between the consumption of the poison and the hospital admission. The average time interval in patients who died was 6 hours 32 minutes.

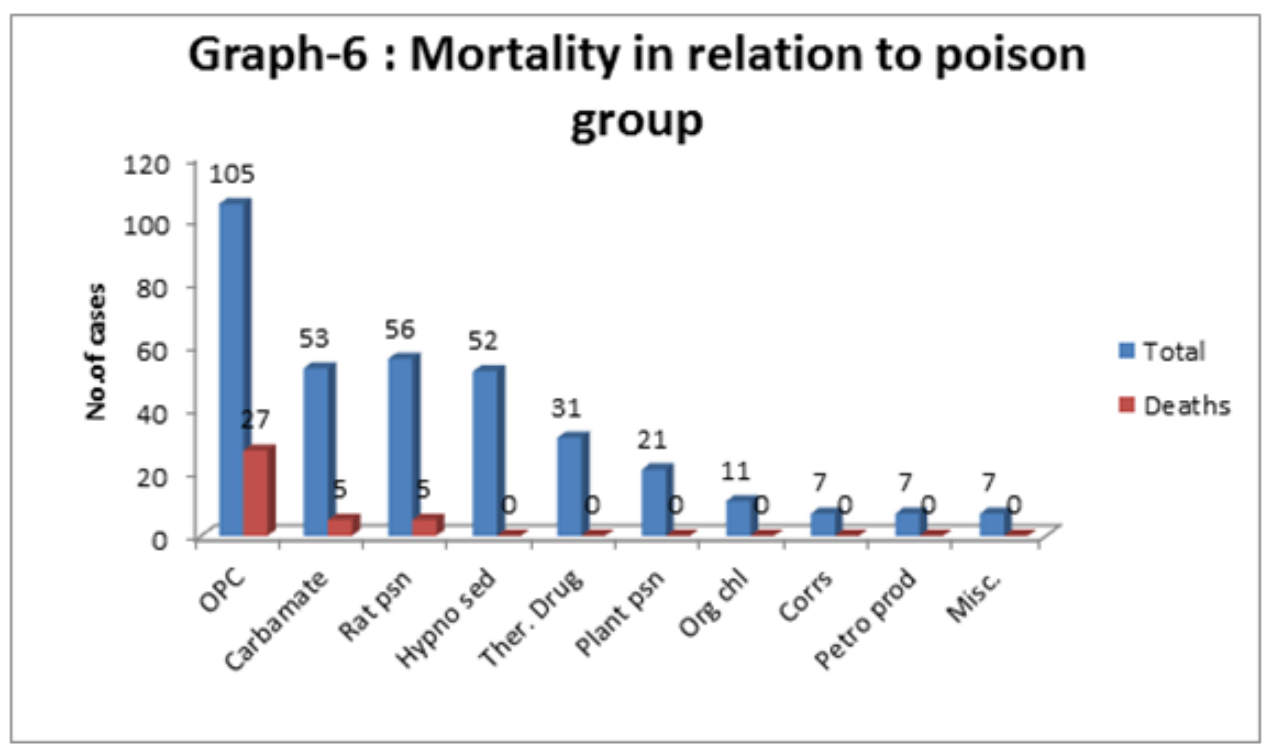




\section{ORIGINAL ARTICLE}
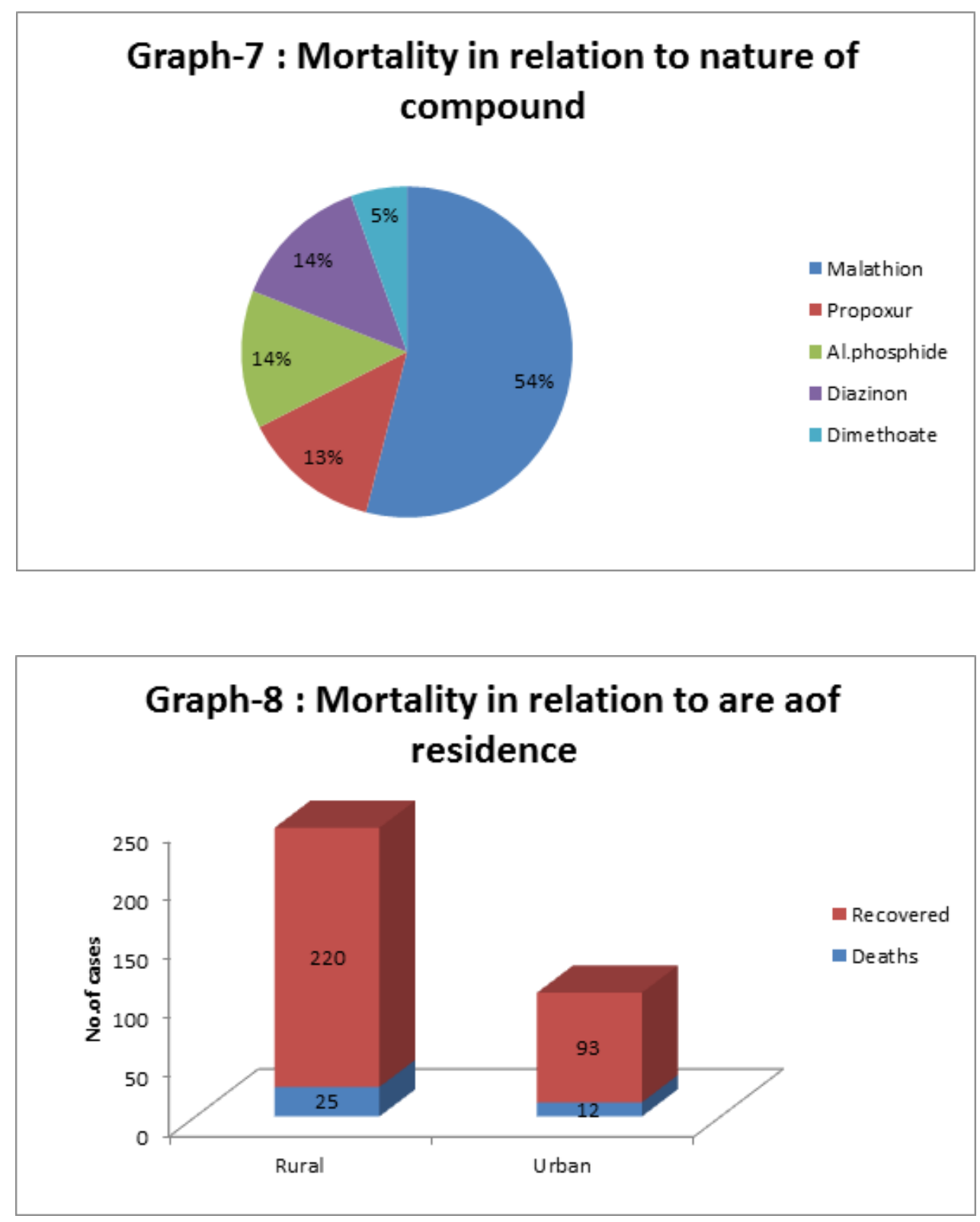

The minimum time interval, maximum time interval and average time interval between those who survived and those who died is shown below

\begin{tabular}{|c|c|c|c|c|}
\hline Outcome & $\begin{array}{c}\text { Minimum time } \\
\text { interval }\end{array}$ & $\begin{array}{c}\text { Maximum time } \\
\text { interval }\end{array}$ & $\begin{array}{c}\text { Average time } \\
\text { interval }\end{array}$ & $\begin{array}{c}\text { Number of } \\
\text { patients }\end{array}$ \\
\hline Survivors & $0: 25$ & $14: 00$ & $3: 00$ & 313 \\
\hline Deaths & $1: 20$ & $21: 00$ & $6: 32$ & 37 \\
\hline \multicolumn{2}{|r|}{ Table 7: Outcome and time interval from consumption of poison to hospitalization }
\end{tabular}




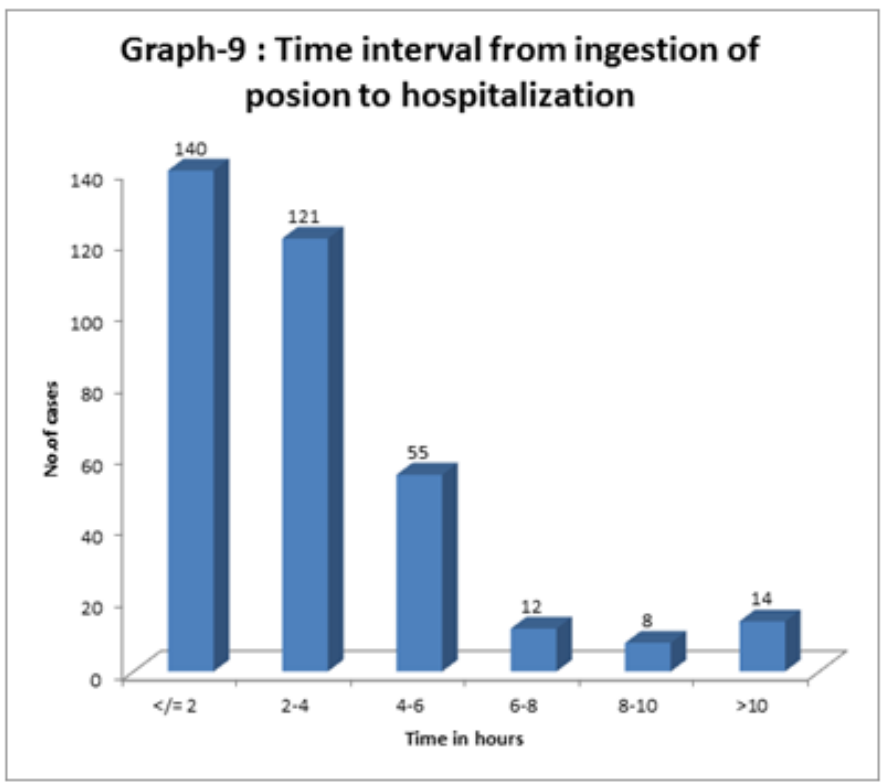

\section{DISCUSSION:}

INCIDENCE: Out of 7657 cases admitted to the Chigateri General Hospital and Bapuji Hospital, attached to J.J.M. Medical College, Davangere during the study period, 350 cases were due to acute poisoning constituting of $4.57 \%$ of the hospital admissions.

AGE: Out of the 350 cases of acute poisoning studied, the minimum age was 18 years and the maximum age was 60 years. The average age of the patients was 26.55 years.

The majority of the patients were in the 20-30 years age group. This corresponds to the study of Surjith Singh et $\mathrm{al}^{10}$ who found the average age of 26.3 years in acute poisoning.

SEX DISTRIBUTION: Of the 350 cases studied, there were 268 males and 82 females with a male: female ratio of 76.5:23.4.

Poisoning was more common in males $<30$ years of age $\left(\mathrm{X}^{2}=8.57, \mathrm{P}=0.003\right)$.

URBAN AND RURAL DISTRIBUTION: Of the 350 cases studied, 245 hailed from rural areas while 105 were from urban areas giving an rural: urban ratio of 70:30.

TYPE OF POISON: In the present study, Organophosphorous compounds were the commonest (30\%), followed by rat poison (16\%), carbamates $(15 \%)$, hypnosedative $(15 \%)$, therapeutic drugs $(9 \%)$, plant poison $(6 \%)$, organochlorine $(3 \%)$, corrosive $(2 \%)$ and petroleum products and miscellaneous $2 \%$ each.

TIME INTERVAL BETWEEN CONSUMPTION AND HOSPITALIZATION: The time interval from ingestion of the poison and admission to the hospital ranged between a minimum of 25 minutes to a maximum of 21 hours and the majority of the patients reached hospital before 3 hours of poison consumption. 
CLINICAL FEATURES: Of the 350 cases studied, 112 were in altered sensorium (32\%) and 20 were in coma $(5.7 \%)$ at the time of admission to the hospital.

Bradycardia was observed in 30 patients (8.5\%), mainly in rat poison and < hypnosedative groups. Tachycardia was noted in 52 patients (14.85\%) mainly in those who had consumed Datura and Salicylates In our study, hypotension was noted in 21 cases (6\%) while $329(94 \%)$ patients had hypertension at the time of admission

Tachypnoea was observed in 4 cases (1.14\%) especially in those who had consumed Datura and Salicylates. Pupillary size was observed and found to be constructed in 201 cases (57.42\%), dilated in 9 cases $(2.57 \%)$ and was normal in 140 cases (40\%).

The pupil was reactive to light in 160 patients $(45.71 \%)$ and it was non-reactive to light in 190 patients $(54.28 \%)$. Fasciculations were present in 42 cases $(12 \%)$ in this study at the time of admission.

MORTALITY: Mortality in the present study is $10.57 \%$. Mortality was significantly higher in OP poisoning group (72.9\%) compared to other poisoning group $\left(\mathrm{X}^{2}=36.38, \mathrm{P}=0.0001\right)$.

SUMMARY AND CONCLUSION: The history, nature of the poisons commonly ingested, clinical features and management of acute poisoning are considered. The available literature on acute poisoning is discussed. Out of 7657 cases admitted, 350 were admitted for acute poisoning between $1^{\text {st }}$ March 2011 to 31st October 2011.

Detailed history of each cases is taken and all patients were examined in detail with relevant investigations. The patients were managed according to type of the poison ingested.

Factors such as age, sex, place of residence and time interval between consumption of poison and admission to hospital are discussed. The incidence of poisoning and death were analyzed with respect to place of residence (urban or rural) and type of compound consumed.

\section{From this study, following conclusions are made:}

1. Majority of the patients (50.5\%) belonged to age group of 20-30 years.

2. Majority of the patients belonged to urban group $70 \%$.

3. Majority of the patients $76.57 \%$ were males.

4. Organophosphorous compounds were the commonest (30\%), followed by rat poison (16\%), carbamates (15\%), hypnosedative (15\%), therapeutic drugs $(9 \%)$, plant poison (6\%), organochlorine (3\%), corrosive (2\%) and petroleum products and miscellaneous $2 \%$ each.

5. All the cases were of suicidal intent.

6. $49.5 \%$ of cases were brought to the hospital within two hours of ingestion of the poison.

7. The average time interval from consumption of poison to hospitalization was 3 hours.

8. $32 \%$ of cases showed altered consciousness and $5.7 \%$ were in coma at the time of admission.

9. Bradycardia was noted in $8.57 \%$ of cases while tachycardia was present in $14.85 \%$ of cases.

10. Constriction of pupils was seen in $57.42 \%$ of cases while dilation was noted in $2.57 \%$ cases.

11. Pupils were reactive to light in $45.7 \%$ cases while in $54.28 \%$ it was nonreactive.

12. Fasciculations were found in $12 \%$ cases.

13. 20 cases $(5.7 \%)$ were referred to specialized centers.

14. Of the total 350 cases, there were 37 deaths giving a mortality rate of $10.57 \%$. 
15. Of the patients who died, $73 \%$ were due to organophosphorous poisoning followed by $13.5 \%$ due to rat poison and $13.5 \%$ due to carbamate.

16. Majority of the deaths were from rural sector $(67.56 \%)$.

\section{BIBLIOGRAPHY:}

1. Karathiedde L Senanayake. O.P. insecticide poisoning. Br J Anaesthesia 1989; 63: $\quad$ 736-750.

2. Namba Tastuji, Carl Nolte T, Jerald Jackrel. Poisoning due to O.P insecticides, acute and chronic manifestations. Am J Medicine 1971; 475 - 492.

3. Laurence DR - Clinical Pharmacology, 7th ed. 1992.

4. Namba Tastuji. Cholinesterase inhibition by O.P. Compound and its Clinical effects. WHO Bulletin 1971; 44; 289 - 307.

5. Birdstrupp PL. Poisoning by O.P compounds. BMJ 1950; 2; 548.

6. Mutalik GS, Wadia RS. Poisoning by diazinon, an O.P. insecticide. JIMA 1962; 38; 2; 67-71.

7. Vishwanathan et al. poisoning by bug poison preliminary study. JIMA 1962; 39; 345.

8. Tasher TS. Study of mortality rate in acute poisoning and its characters in a region with developed agriculture. VUTR BOLES 1988; 84 - 88.

9. Singh S, Sharma BK, Wahi PL. Spectrum of acute poisoning in adults (10 years experience). JAP11984; 32: 561 - 563.

10. Surjith Singh et al. Changing Pattern of Acute Poisoning in Adults: Experience of a Large NorthWest Indian Hospital (1970-1989). JAPI 1997:45:3:194-96.

\section{AUTHORS:}

1. Panduranga M. S.

2. Rangaswamy

\section{PARTICULARS OF CONTRIBUTORS:}

1. Assistant Professor, Department of General Medicine, Mysore Medical College, Mysore.

2. Assistant Professor, Department of General Medicine, Mysore Medical College, Mysore.

\section{NAME ADDRESS EMAIL ID OF THE} CORRESPONDING AUTHOR:

Dr. Panduranga M. S,

Assistant Professor,

Department of General Medicine,

Mysore Medical College,

Mysore-570001.

Email: drpandu85@gmail.com

Date of Submission: 30/08/2014.

Date of Peer Review: 01/09/2014.

Date of Acceptance: 10/09/2014.

Date of Publishing: 17/09/2014. 